\title{
Variable Presentations in Pulmonary Arteriovenous Malformation
}

\author{
Nasir Ahmad Lone ${ }^{\odot}$, Akshit Kumar ${ }^{\circledR}$, Waseem Ahmed Sheikh ${ }^{\circledR}$ \\ Senior Resident, Department of Radiodiagnoses, Sher - i - Kashmir Institute of Medical Sciences, Soura, Jammu and Kashmir, India.
}

\section{Abstract}

Pulmonary arteriovenous malformations (PAVM) are a group of vascular anomalies of lung which present with variable clinical symptoms. Most patients with PAVM are asymptomatic but it can cause dyspnea on exertion, paradoxical emboli to brain causing various central nervous system complications like stroke and brain abscess, hemoptysis and rupture. The age at the presentation can range from 1st to 7 th decade but the majority of patients present before the age of 30 years. PAVM is strongly associated with hereditary haemorrhagic telangiectasis which presents with epistaxis, mucocutaneous telangiectasias and AV malformations of various organs. In our case series, we have patients ranging from 3 yrs to 75 years with presentation ranging from asymptomatic to exertional dyspnea, hemoptysis and neurological complications.

Keywords: Pulmonary arteriovenous malformation, brain abscess, embolisation, hereditary hemorrhagic telangiectasia.

Corresponding Author: Nasir Ahmad Lone, Senior Resident, Department of Radiodiagnoses, Sher - i - Kashmir Institute of Medical Sciences, Soura, Jammu and Kashmir, India.

E-mail: nasirlone06962@gmail.com

Received: 04 June 2020

Revised: 12 July 2020

Accepted: 20 July 2020

Published: 30 December 2020

\section{Introduction}

The first description of PAVM was made by Churton in 1897 who reported PAVM in a 12 year old male presenting with epistaxis, haemoptysis, and pulmonary systolic bruit. On postmortem examination he was found to have multiple PAVMs bilaterally. ${ }^{[1]}$ Rhodes established that PAVMs are associated with telangiectasias in $1938 .{ }^{[2,3]}$

In 1942, Hepburn and Dauphinee performed successful surgical removal of pulmonary haemangioma. ${ }^{[4]}$ Packard and Waring performed surgical ligation of pulmonary artery to treat PAVM as an alternative to lung parenchymal resection in 1945. Surgical intervention remained the mainstay of treatment until 1978 when Taylor performed first successful percutaneous arterial embolisation of a PAVM. ${ }^{[5]}$

\section{Pathophysiology}

There is an abnormal communication between the pulmonary arteries and the pulmonary veins in PAVMs. Desaturated blood returns to the pulmonary veins bypassing the pulmonary capillaries where oxygen exchange takes place. As the amount of desaturated blood returning to the left heart becomes significant, cyanosis results. PAVMs are found mostly in the lower lobes, and it is the lower lobes through which most of the blood is directed in upright position. In patients with significant shunt through a large or multiple PAVMs, orthodeoxia results which is fall in arterial oxygenation levels in upright posture. ${ }^{[6]}$

Larger particles can pass unfiltered through a big PAVM into the systemic circulation resulting in paradoxical embolisation which may lead to stroke and septic embolisation. A classification system of PAVMs has been described by Anabtawi and coworkers who classified PAVMs into five groups based on embryology of the lung and pulmonary vasculature. ${ }^{[7]}$

\section{$\underline{\text { Anatomical classification of PAVMs. }}{ }^{[8]}$}

Group IMultiple small arteriovenous fistulas with no aneurysm.

Group IILarge arteriovenous aneurysm.

Group IIILarge arteriovenous aneurysm (central). Large arteriovenous aneurysm with anomalous venous drainage. Multiple small arteriovenous fistulas with anomalous venous drainage.

Group IV Large venous aneurysm with systemic artery communication. Large venous aneurysm without fistula.

Group V Anomalous venous drainage with fistulas. 


\section{Aetiology}

Most of the PAVMs are congenital constituting around $80 \%$ of all cases, and out of these most are associated with hereditary hemorrhagic telangiectasia(HHT). ${ }^{[9,10]}$ Approximately $15 \%$ of patients with HHT have a PAVM in their lungs. ${ }^{[1-15]}$ In pre sence of symptoms and signs of either of these two entities, the possibility that both may coexist must be evaluated. In patients with HHT, telangiectasia develop in the skin and mucosa of oral/nasal cavity and conjunctiva usually becoming apparent by third decade. ${ }^{[9,10]}$

Secondary or acquired PAVMs are less frequent in occurence. Secondary PAVM develops due to chest trauma or surgery, chronic liver disease, mitral stenosis, infections like actinomycosis, and amyloidosis. ${ }^{[16,17]}$

An increased rate of growth of PAVM has been found in pregnancy with increase in associated complications due to increased blood volume and cardiac output which leads to increased blood flow through lungs, preferentially across the PAVM. ${ }^{[8]}$

\section{Clinical Presentation}

Mostly patients are asymptomatic accounting for upto $60 \%$ in some studies. ${ }^{[9,11-13]}$ These patients are incidentally detected on imaging studies. [Figure 6,7]

Patients with underlying HHT often show symptoms attributable to this disorder including epistaxis and mucocutaneous telangiectasia. PAVMs should always be considered in patients presenting with unexplained dyspnea or hypoxemia as well as in patients with nodules and a history of a stroke or brain abscess at a young age.

Symptoms related to PAVMs typically begin during fourth to sixth decades of life, whereas symptoms of HHT usually develop in first two decades of life like epistaxis secondary to nasal telangiectasia or appearance of telangiectasia on the skin and lips. ${ }^{[14]}$

The frequency as well as severity of symptoms tends to be greater among those who have large PAVMs, multiple PAVMs, a large shunt fraction, or HHT, although it has not been shown in all studies.

\section{Dyspnea}

In patients who present with symptoms of PAVM, dyspnoea on exertion is most common seen in upto $67 \%$ of cases. ${ }^{[9,10]}$

Dyspnea is especially common among patients who have large, multiple, bilateral, or diffuse PAVMs. [Figures 3-5]

\section{Platypnea and Orthodeoxia}

Platypnea is dyspnoea induced by the upright position and relieved in recumbent position. It results because of increased blood flow through the dependent portions of lungs where most of PAVMs are located, in the upright position. Platypnea is a classic but rare symptom in patients with PAVMs. ${ }^{[15]}$

In contrast, several studies have found orthodeoxia (ie, a decrease in the oxyhemoglobin saturation by 2 percent or more in upright position than in supine position) in at least $30 \%$ of patients. ${ }^{[15]}$

\section{Hemoptysis and Hemothorax}

Hemothorax and hemoptysis occur in less than 10 to 20 percent of patients with PAVMs, but are potentially lifethreatening. ${ }^{[18]}$ Hemothorax results due to rupture of a PAVM in subpleural location, while hemoptysis results due to rupture of a parenchymal PAVM or an endobronchial telangiectasia. [Figure 1,3-5]

The chances of pulmonary hemorrhage increase during pregnancy, especially during the third trimester, as increased blood volume and increased vascular distensibility in pregnancy lead to increased blood flow through PAVMs.

\section{Neurological Complications}

Neurologic complications occur in upto $41 \%$ of patients of PAVM as per several large studies published since 2004. ${ }^{[18-20]}$ The most common neurologic complications are stroke and brain abscess likely due to paradoxical embolisation. Patients also present with seizures, hemorrhage, headaches and sometimes with syncope, diplopia and tinnitus. ${ }^{[19,20]}$ Higher rates of these complications have been reported in patients with diffuse or large PAVMs. ${ }^{[13,21,22]}$

Paradoxical embolization is the most likely mechanism for stroke and cerebral abscess formation and this is supported by their increased occurrence in patients with feeding arteries $>2$ to $3 \mathrm{~mm}$ in diameter [Figures 8-11]. The mechanism for seizures, migraines, and other neurologic symptoms is less clear but may be secondary to cerebral hypoxia due to shunting through PAVMs.

\section{Role of Imaging In Pulmonary Avms. ${ }^{[13]}$}

1. Chest Radiography - typical chest radiographic findings include a smooth nodule(s) with linear parallel shadows leading towards the hilum representing the feeding and draining vessels.

2. Computed Tomography - CT is more sensitive than conventional chest radiography for detection of PAVMs. This 
is because on chest radiography, small PAVMs can be easily missed and discrete PAVMs are occasionally obscured by the diaphragms, heart shadow, or concomitant parenchymal lung disease. CT identifies nearly all PAVMs, even those that are poorly appreciated on conventional chest radiographs and so $\mathrm{CT}$ remains the preferred imaging modality for diagnosis.

Typical CT imaging characteristics that together are considered diagnostic include the following

- Round or oval nodule or mass of uniform density.

- Well demarcated smooth borders with occasional lobulation

- Usually 0.5 to $5 \mathrm{~cm}$ in diameter, but sometimes exceeding $10 \mathrm{~cm}$ in diameter.

- Usually 2 to 8 lesions among the patients who have multiple PAVMs.

- Visible feeding vessels that are visualized on CT as tubular structures that blend into/terminate at the sac. Vessels are also typically larger than other vessels in the vicinity.

Atypical findings on CT include an irregular sac with poorly defined borders, only one vessel leading into the sac, a vessel that continues past the nodule/sac, and irregular or no contrast enhancement.

3. Pulmonary Angiography- Pulmonary angiography remains the gold standard for defining the anatomy of PAVMs identified previously on CT that are considered potentially suitable for embolotherapy but is also occasionally performed for the sole purposes of definitive diagnosis .Typical findings include the demonstration of contrast-enhancement with a feeding artery leading to the abnormal arteriovenous malformation drained by a pulmonary vein. However, smaller PAVMs (with sacs $<0.5 \mathrm{~cm}$ ) may fail to show definitive contrast-enhancement.

4. Magnetic Resonance Angiography - Although magnetic resonance imaging may show similar findings to those seen on $\mathrm{CT}$, it is not as sensitive or as specific diagnostically. It is also more expensive and highly specialized expertise is required for accurate interpretation.

\section{$\underline{\text { Treatement Considerations }}$}

Not all PAVMs require intervention. When indicated, most of the patients are treated with embolotherapy, which involves occlusion of the feeding vessels to a PAVM under imaging guidance. Selecting whom to treat depends upon several factors including the feeding artery diameter (FAD), PAVMrelated symptoms, and the patient's ability to tolerate the procedure. ${ }^{[23,24]}$

Patients who have one or more PAVMs with a FAD $\geq 2$ to $3 \mathrm{~mm}$ on chest computed tomography (CT), regardless of the severity of symptoms, pulmonary angiography and embolotherapy is usually advocated. ${ }^{[13,24,25]}$

In patients with atypical lesions or PAVMs with FAD $<2 \mathrm{~mm}$ that are accompanied by symptomatic hypoxemia, paradoxical embolism, or hemoptysis; embolotherapy results in an abrupt improvement in the radiographic appearance, symptoms, and in oxygenation levels. ${ }^{[26]}$

Patients with asymptomatic PAVMs in whom the feeding artery is $<2 \mathrm{~mm}$ are usually followed with yearly clinical observation, and a non-contrast CT every three to five years. PAVMs that progressively enlarge or become symptomatic during follow-up should undergo evaluation for embolotherapy with pulmonary angiography.

Patients who fail embolization or in whom recanalization or new PAVMs develop following embolotherapy, repeated embolization is recommended. Surgery remains an option for patients who fail repeated embolization as well as for patients whose lesions are suitable for intervention but are deemed not amenable for endovascular procedure by an experienced radiologist. Those patients who present with life threatening hemorrhage from ruptured PAVM are also taken for surgery in a facility without access to angioembolisation.

\section{Case Series}

\section{Case 1:}

70 years male patient who presented with history of recurrent hemoptysis. On NCCT chest initially ,he was diagnosed as a case of organizing consolidations, but as hemoptysis persisted, $\mathrm{CT}$ angio was done which showed AVM in right middle lobe as shown in [Figure 1].

\section{Case 2:}

A 75 years female patient presented with dyspnoe to emergency department.NCCT chest showed hemothorax on right side with varying density. CT pulmonary angiography was done which showed two large pulmonary AVMs with one of the AVMs showing active contrast extravasation. So this case presented as a case of hemothorax secondary to spontaneous rupture of pulmonary AVM [Figures 2-5]

\section{Case 3:}

A 21 year old male patient who was on followup as a treated case of lower limb osteosarcoma. On followup CECT a pulmonary AVM was noted in right lower lobe as an incidental finding.So pulmonary AVM can be asymptomatic and present as an incidental finding on routine imaging [Figure 6,7]. 


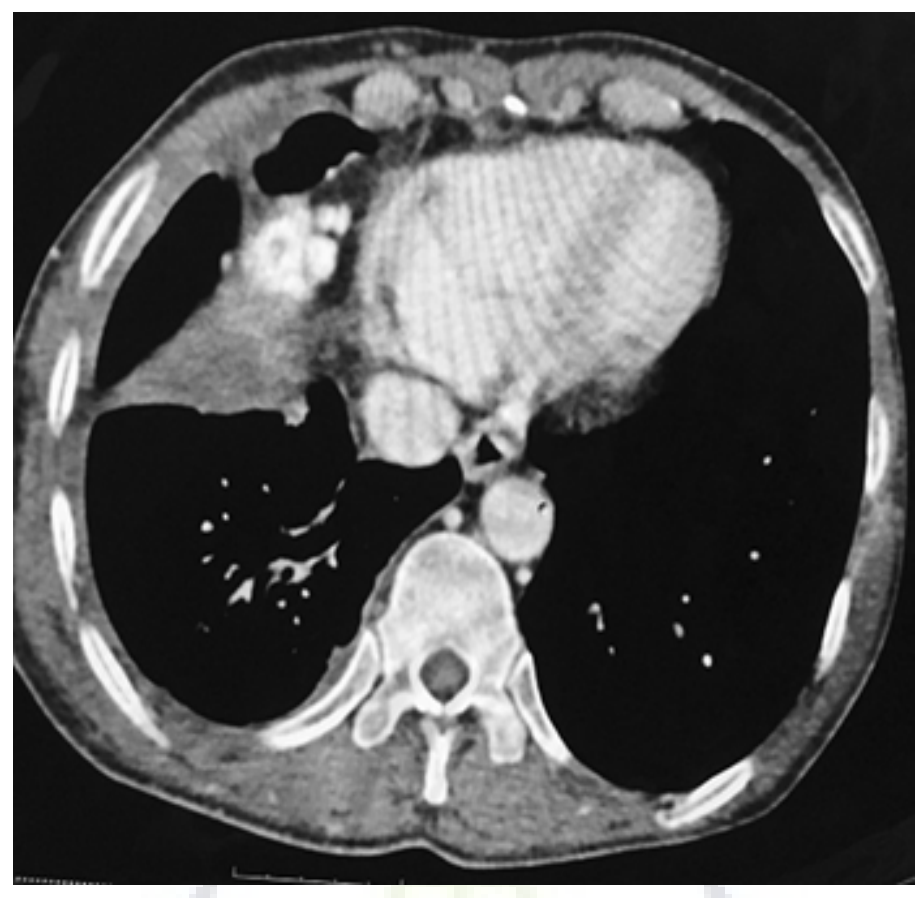

Figure 1: Axial CT angiographic image of 70 years male patient showing AVM in right middle lobe with associated consolidation.

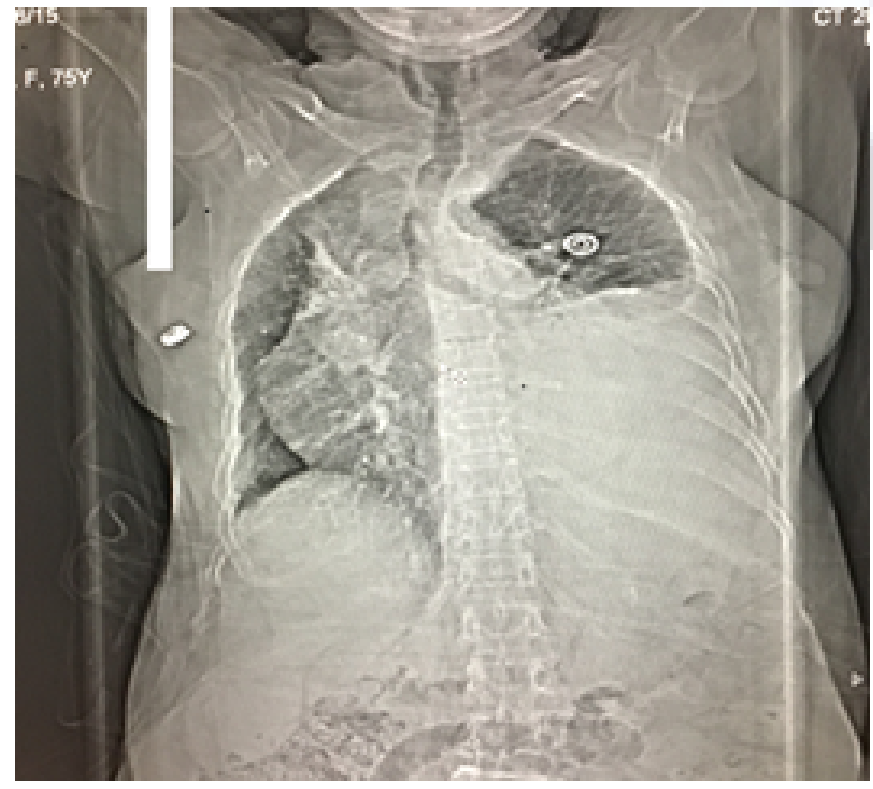

Figure 2: CTtopogram showing moderate to large left pleural effusion.

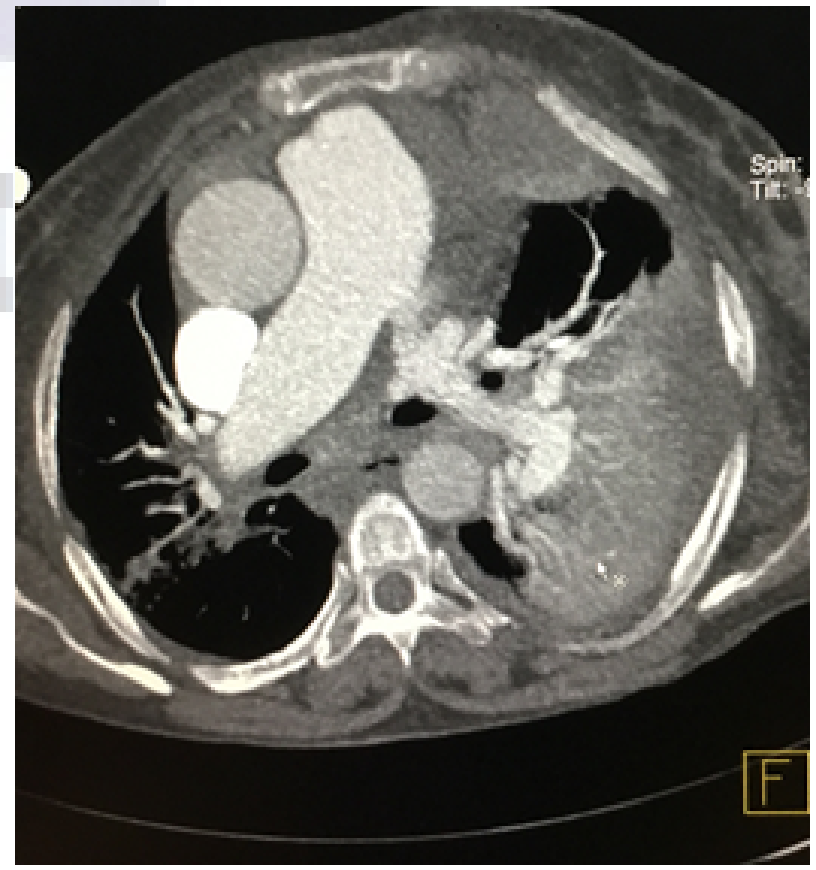

Figure 3: Axial CT angiographic image in same patient showing left lower lobe AVM with associated high density pleural collection. 


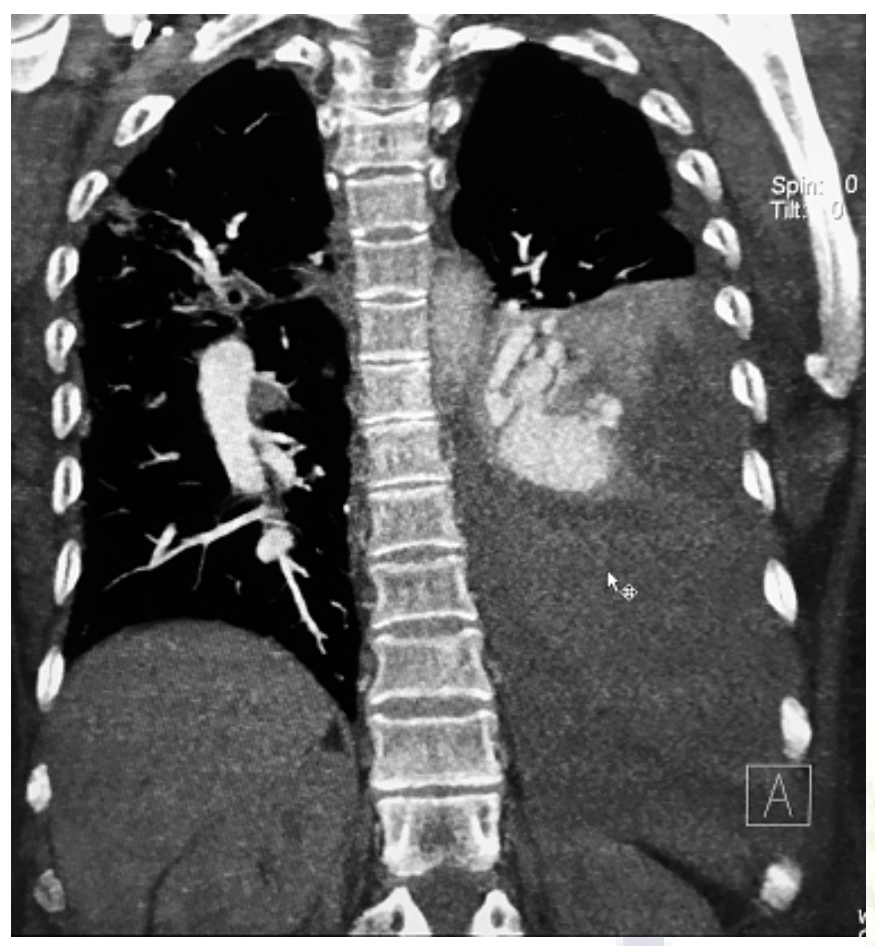

Figure 4: Coronal and axial CT angiographic images in same patient showing AVM in left lower lobe with active contrast extravasation.

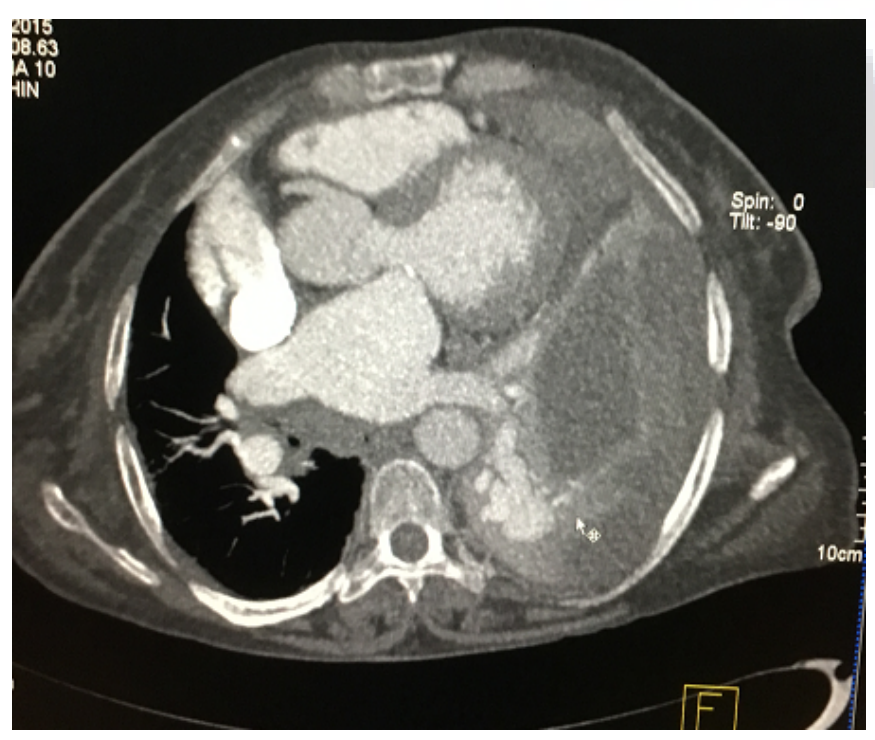

Figure 5: Coronal and axial CT angiographic images in same patient showing AVM in left lower lobe with active contrast extravasation.

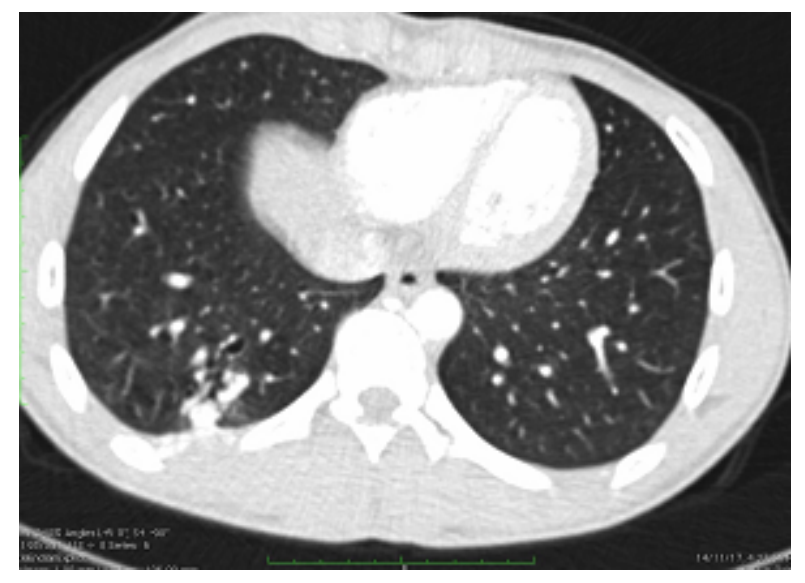

Figure 6: Axial CECT images with lung window showing an enhancing lesion suggestive of AVM in right lower lobe with feeders from intercostal arteries.

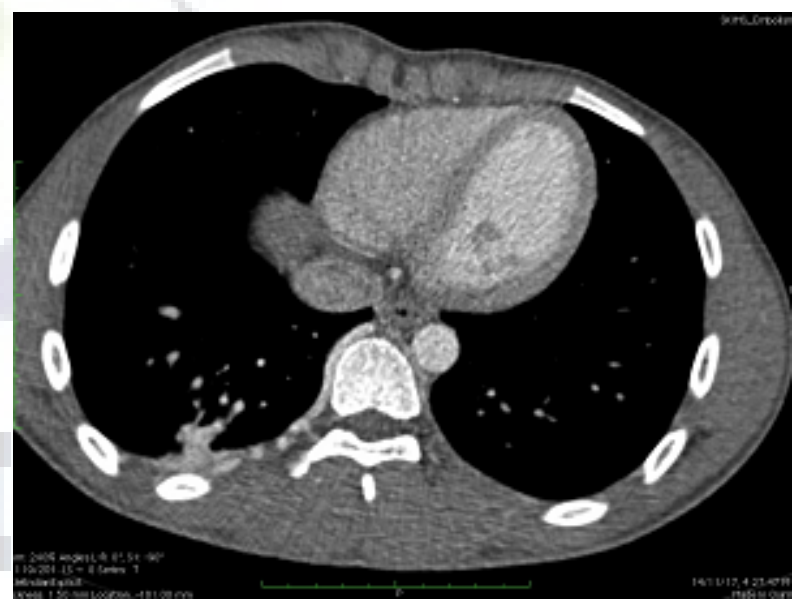

Figure 7: Axial CECT images withMediastinal Window showing an enhancing lesion suggestive of AVM in right lower lobe with feeders from intercostal arteries.

\section{Case 4:}

A 3 year old male patient presented with fever headache and altered sensorium and MRI brain revealed a brain abscess. Chest X-ray revealed an opacity in right lung and CT angio showed evidence of a large pulmonary AVM. The brain abscess in the patient had resulted from paradoxical embolization because of shunting of blood in pulmonary AVM [Figures 8-11] 


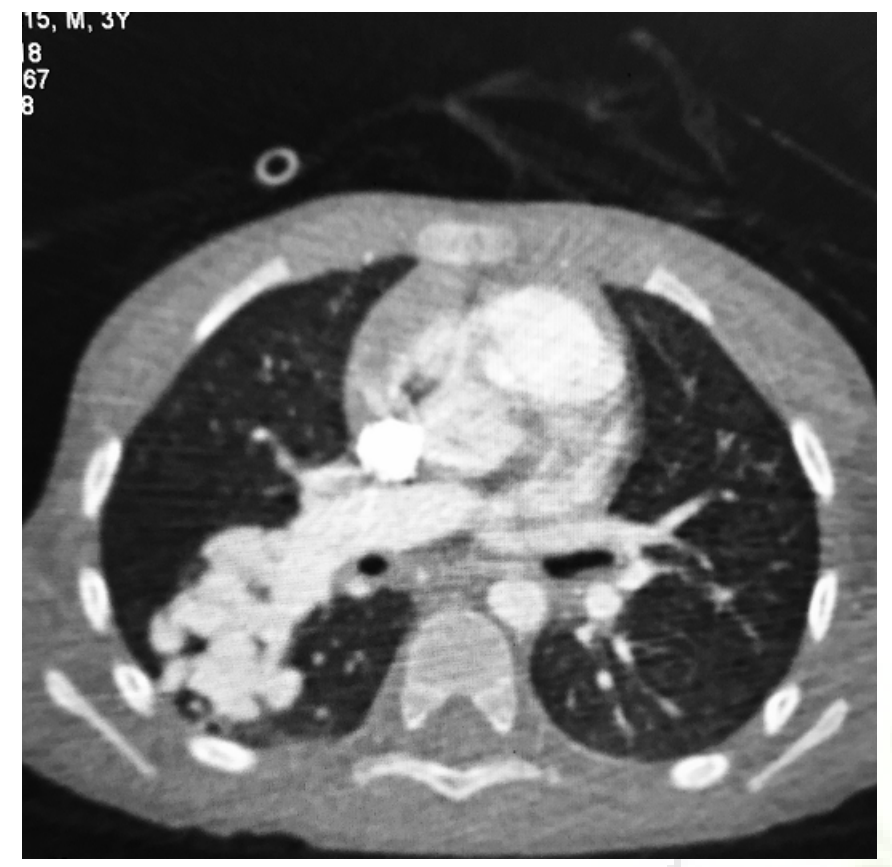

Figure 8: Axial and coronal CT angiographic images in a 3 year old patient showing AVM in right upper lobe with enlarged feeding artery and draining pulmonary veins.

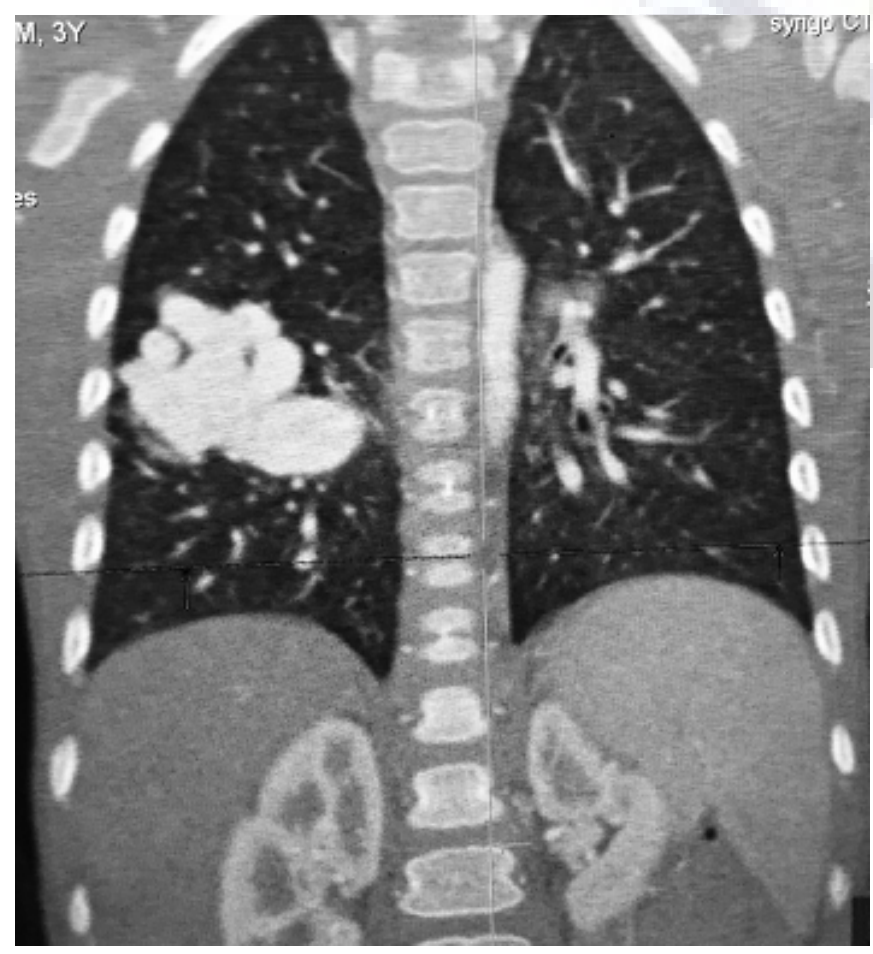

Figure 9: Axial and coronal CT angiographic images in a 3 year old patient showing AVM in right upper lobe with enlarged feeding artery and draining pulmonary veins.

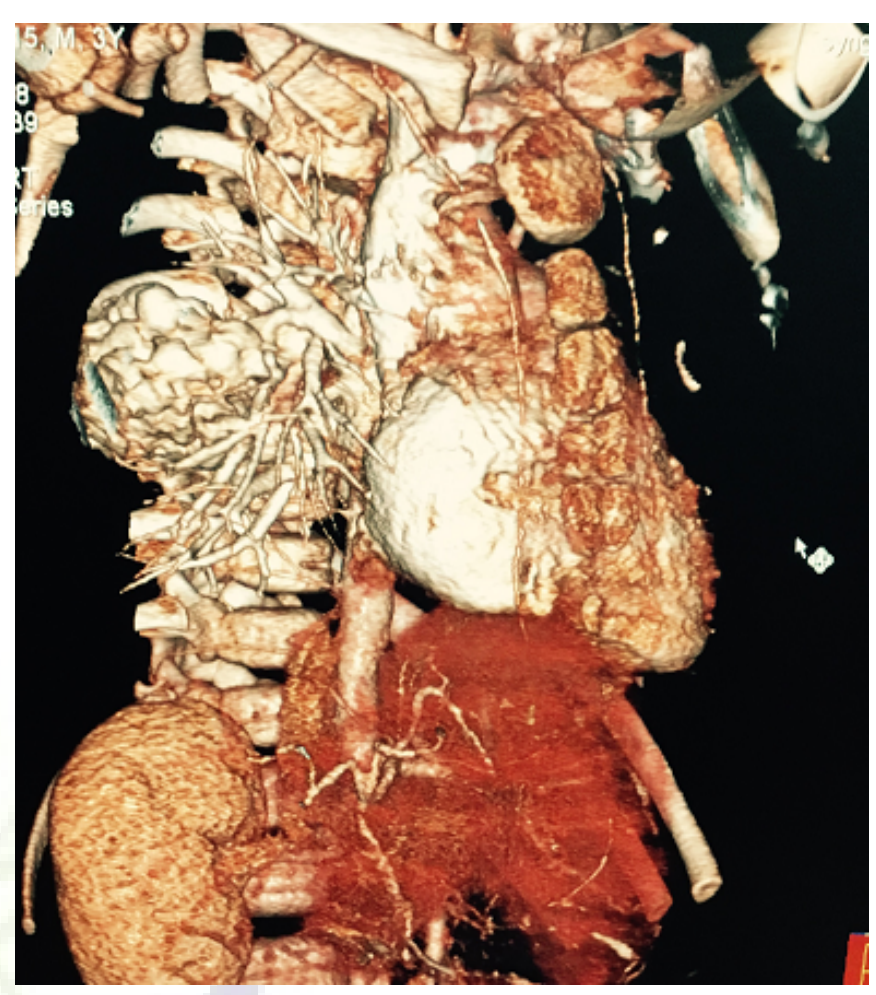

Figure 10: Shaded Surface Display images of the same patient showing alargr AVM in right lung.

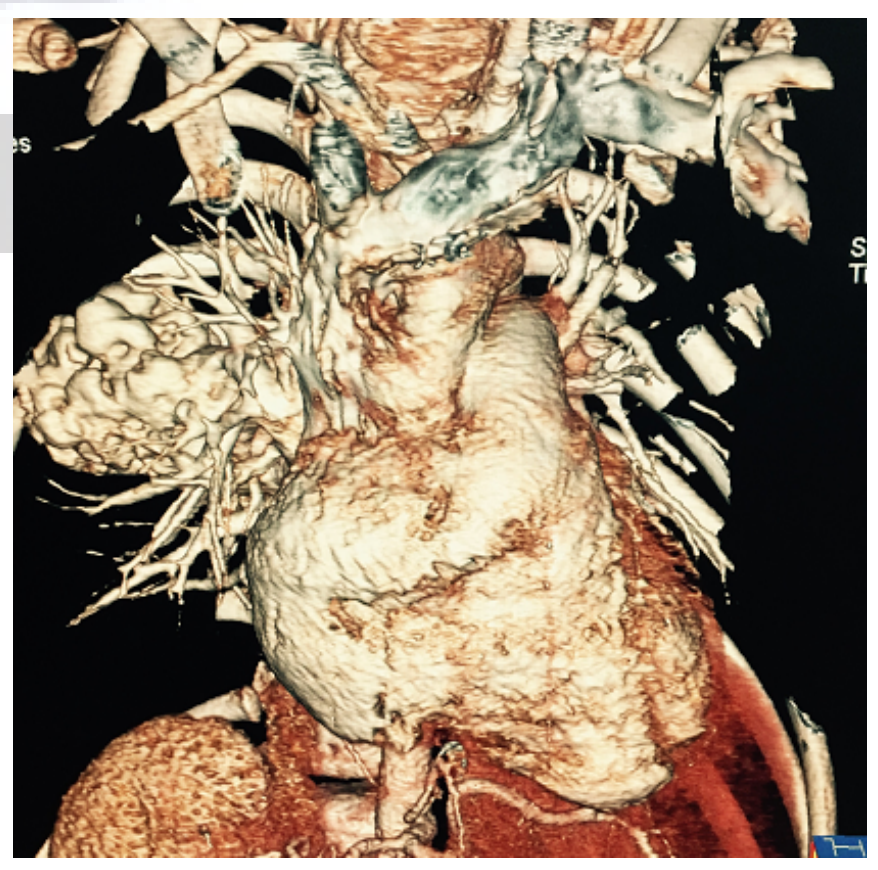

Figure 11: Shaded Surface Display images of the same patient showing a largr AVM in right lung. 


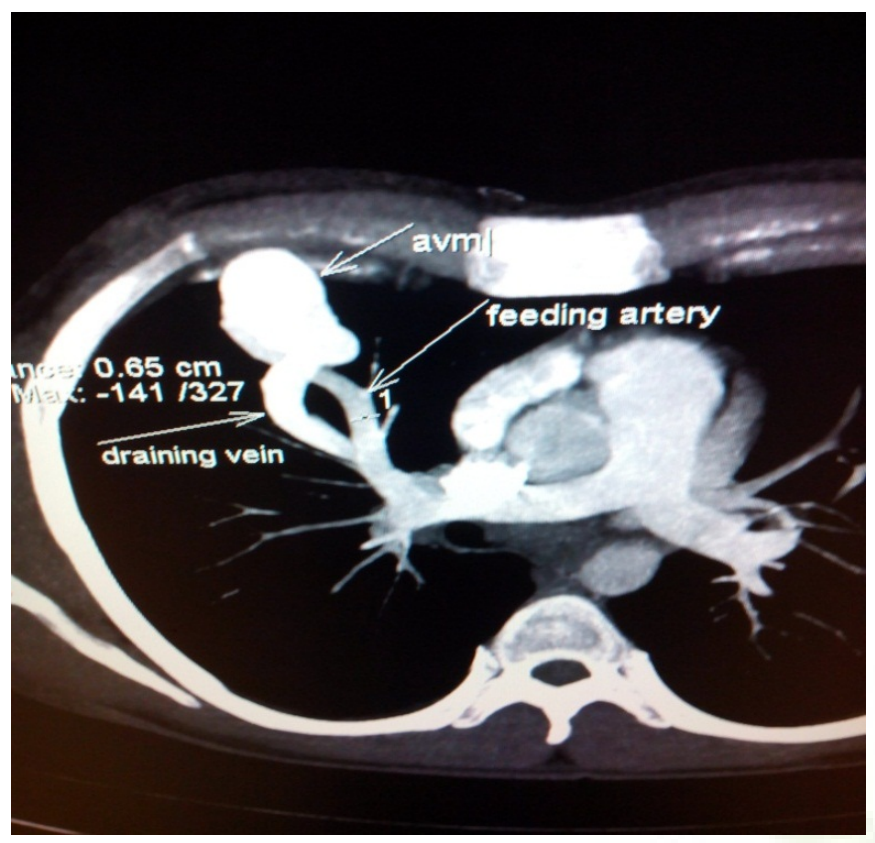

Figure 13: CT angiographic image showing a pulmonary AVM in right upper lobe supplied by a dilated feeding and draining vessel.

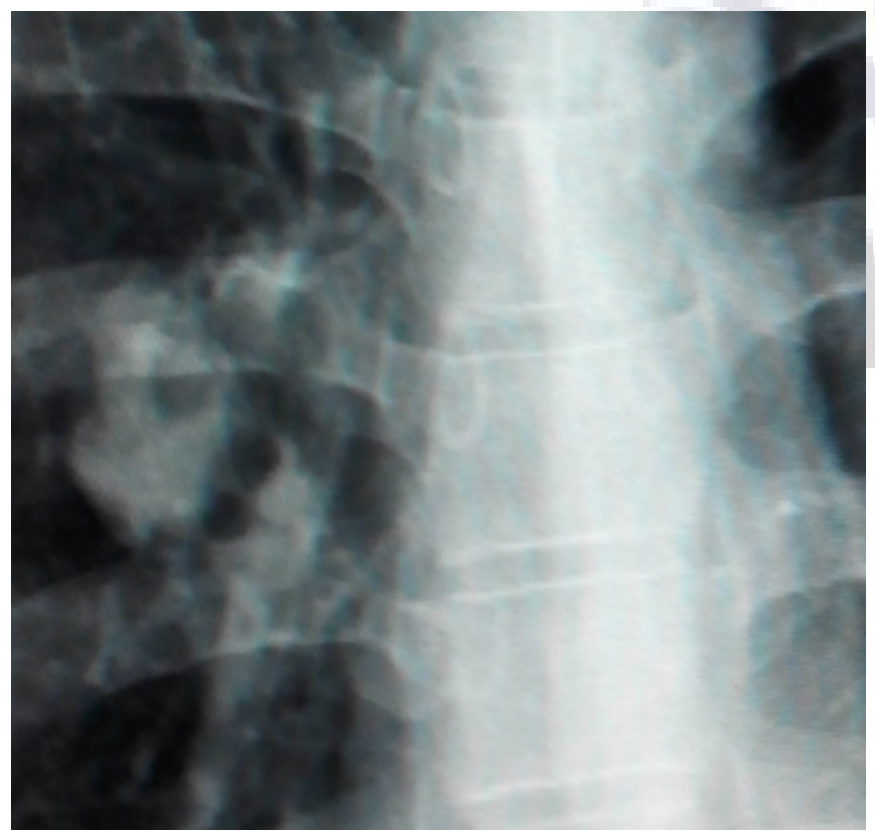

Figure 12: Chest Xray showing a nodulein right upper zone.

\section{Case 5:}

A 28 years old male patient presented with complaints of recurrent epistaxis and mucosal telengiectasia. Chest Xray showed a nodule in right lung. On CECT a pulmonary AVM was noted in right upper lobe. Another AVM was also seen in liver in the same patient and a diagnoses of Hereditary hemorrhagic telangiectasia was made in the patient [Figures $12,13]$

\section{Conclusion}

PAVMs are a rare clinical identity. A strong association between PAVM and HHT exists. Due to variable presentations of this clinical identity, all the patients having telangiectasia with dyspnea, cyanosis or neurological symptoms should be screened for PAVMs. Imaging is the backbone of the diagnosis and for taking the management decision. The chest radiograph sometimes suggest the diagnosis of PAVM, however, it lacks both sensitivity as well as specificity. Contrast enhanced CT angiography and pulmonary angiography are usually diagnostic with high sensitivity and specificity especially for documenting the number and location of all lesions before planning the appropriate management. Embolisation of the PAVMs is safe and effective procedure with fewer complications and it should be the preferred treatment option for PAVMs. Surgical procedure especially lung conserving resection remains an alternative option for those symptomatic patients in whom embolisation fails or in whom it is technically not feasible. Small PAVMs have a potential risk of serial growth and previously occluded ones may recanalise, making regular follow up a must in all cases of PAVMs.

\section{References}

1. Charlton RW, Plessis LAD. Multiple Pulmonary Artery Aneurysms. ThoraxBMJ. 1961;16(4):264-371. Available from: https://dx.doi.org/10.1136/thx.16.4.364.

2. Rhodes CB. Cavernous hemangiomas of lung with secondary polycythemia. JAMA. 1938;110:1914-1919. Available from: https://dx.doi.org/10.1001/jama.1938.62790230002011a.

3. Khurshid I. Pulmonary arteriovenous malformation. Postgrad Med J. 2002;78(918):191-197. Available from: https://dx.doi. org/10.1136/pmj.78.918.191.

4. Hepburn J, Dauphinee JA. Successful removal of hemangioma of lung followed by disapperance of polycythemia. Am J Med. 1942;204:681-688.

5. Taylor BG, Cockerill EM, Manfredi F, Klatte EC. Therapeutic embolization of the pulmonary artery in pulmonary arteriovenous fistula. Am J Med. 1978;64(2):360-365. Available from: https://dx.doi.org/10.1016/0002-9343(78)90066-9.

6. Saboo SS, Chamarthy M, Bhalla S, Park H, Sutphin P, Kay F. Pulmonary arteriovenous malformations: diagnosis. Cardiovasc Diagn Ther. 2018;8(3):325-337. Available from: https://dx.doi.org/10.21037/cdt.2018.06.01.

7. Anabtawi IN, Ellison RG, Ellison LT. Pulmonary Arteriovenous Aneurysms and Fistulas: Anatomical Variations, Embry- 
ology, and Classification. Ann Thorac Surg. 1965;1(3):277285. Available from: https://dx.doi.org/10.1016/s00034975(10)66755-0.

8. Esplin MS, Varner MW. Progression of Pulmonary Arteriovenous Malformation During Pregnancy. Obstet Gynecol Surv. 1997;52(4):248-253. Available from: https://dx.doi.org/ 10.1097/00006254-199704000-00022.

9. Dines DE, Arms RA, Bernatz PE. Pulmonary arteriovenous fistulas. Mayo Clin. 1974;49:460-465.

10. Sluiter-Eringa H, Orie N, Slutier HJ. Pulmonary arteriovenous fistula: diagnosis and prognosis in non-complaint patients. Am Rev Respir. 1969;100:177-84. Available from: https://doi.org/ 10.1164/arrd.1969.100.2.177.

11. Dines DE, Deward JB, Bernatz PE. Pulmonary arteriovenous fistula. Mayo Clin. 1983;58:176-81.

12. Sluiter-Eringa H, Orie N, Slutier HJ. Pulmonary arteriovenous fistula: diagnosis and prognosis in non-complaint patients. Am Rev Respir. 1969;100(2):177-84. Available from: https://doi. org/10.1164/arrd.1969.100.2.177.

13. Gossage JR, Kanj G. Pulmonary Arteriovenous Malformations. Am J Respir Crit Care Med. 1998;158(2):643-661. Available from: https://dx.doi.org/10.1164/ajrccm.158.2.9711041.

14. Plauchu H, Chadarévian JPD, Bideau A, Robert JM. Agerelated clinical profile of hereditary hemorrhagic telangiectasia in an epidemiologically recruited population. Am J Medi Genet. 1989;32(3):291-297. Available from: https://dx.doi.org/10. 1002/ajmg.1320320302.

15. Santhirapala V, Chamali B, McKernan H, Tighe HC, Williams LC, Springett JT, et al. Orthodeoxia and postural orthostatic tachycardia in patients with pulmonary arteriovenous malformations: a prospective 8-year series. Thorax. 2014;69(11):1046-1047. Available from: https://dx.doi.org/10. 1136/thoraxjnl-2014-205289.

16. SYMBAS PN, GOLDMAN M, ERBESFELD MH, VLASIS SE. Pulmonary Arteriovenous Fistula, Pulmonary Artery Aneurysm, and Other Vascular Changes of the Lung From Penetrating Trauma. Ann Surg. 1980;191(3):336-340. Available from: https://dx.doi.org/10.1097/00000658-19800300000013.

17. Kamei K, Kusumoto K, Suzuki T. Pulmonary Amyloidosis with Pulmonary Arteriovenous Fistula. Chest. 1989;96:14351436. Available from: https://dx.doi.org/10.1378/chest.96.6. 1435.

18. Cottin V, Chinet T, Lavolé A, Corre R, Marchand E, ReynaudGaubert M, et al. Pulmonary Arteriovenous Malformations in Hereditary Hemorrhagic Telangiectasia. Medicine. 2007;86(1):1-17. Available from: https://dx.doi.org/10.1097/ md.0b013e31802f8da1.
19. Swanson KL, Prakash UBS, Stanson AW. Pulmonary Arteriovenous Fistulas: Mayo Clinic Experience, 1982-1997. Mayo Clin Proc. 1999;74(7):671-680. Available from: https: //dx.doi.org/10.4065/74.7.671.

20. Wong HH, Chan RP, Klatt R, Faughnan ME. Idiopathic pulmonary arteriovenous malformations: clinical and imaging characteristics. Eur Respir J. 2011;38(2):368-375. Available from: https://dx.doi.org/10.1183/09031936.00075110.

21. Faughnan ME, Lui YW, Wirth JA, Pugash RA, Redelmeier DA, Hyland RH, et al. Diffuse Pulmonary Arteriovenous Malformations. Chest. 2000;117(1):31-38. Available from: https://dx.doi.org/10.1378/chest.117.1.31.

22. Moussouttas M, Fayad P, Rosenblatt M, Hashimoto M, Pollak J, Henderson K, et al. Pulmonary arteriovenous malformations: Cerebral ischemia and neurologic manifestations. Neurology. 2000;55(7):959-964. Available from: https://dx.doi.org/10. 1212/wnl.55.7.959.

23. Majumdar S, McWilliams JP. Approach to Pulmonary Arteriovenous Malformations: A Comprehensive Update. J Clin Med. 2020;9(6):1927. Available from: https://dx.doi.org/ $10.3390 / \mathrm{jcm} 9061927$.

24. Mager JJ, Overtoom TTC, Blauw H, Lammers JWJ, Westermann CJJ. Embolotherapy of Pulmonary Arteriovenous Malformations: Long-term Results in 112 Patients. J Vas Interv Radiol. 2004;15(5):451-456. Available from: https://dx.doi. org/10.1097/01.rvi.0000126811.05229.b6.

25. Trerotola SO, Pyeritz RE. PAVM Embolization: An Update. American Journal of Roentgenology. 2010;195(4):837845. Available from: https://dx.doi.org/10.2214/ajr.10.5230. doi:10.2214/ajr.10.5230.

26. Cottin V, Plauchu H, Bayle JY, Barthelet M, Revel D, Cordier JF. Pulmonary Arteriovenous Malformations in Patients with Hereditary Hemorrhagic Telangiectasia. Am J Respir Crit Care Med. 2004;169(9):994-1000. Available from: https://dx.doi. org/10.1164/rccm.200310-1441oc.

Copyright: (C) the author(s), 2020. It is an open-access article distributed under the terms of the Creative Commons Attribution License (CC BY 4.0), which permits authors to retain ownership of the copyright for their content, and allow anyone to download, reuse, reprint, modify, distribute and/or copy the content as long as the original authors and source are cited.

How to cite this article: Lone NA, Kumar A, Sheikh WA. Variable Presentations in Pulmonary Arteriovenous Malformation. Asian J. Med. Radiol. Res. 2020;8(2):1-8.

DOI: dx.doi.org/10.47009/ajmrr.2020.8.2.1

Source of Support: Nil, Conflict of Interest: None declared. 